\title{
Retrospective analyses of dogs found serologically positive for Ehrlichia canis in Cebu, Philippines from 2003 to 2014
}

\author{
Adrian P. Ybañez ${ }^{1,2,3}$, Rochelle Haidee D. Ybañez ${ }^{1}$, Rex R. Villavelez², Honey Pearl F. Malingin²,
} Dana Natasha M. Barrameda ${ }^{1}$, Sharmaine V. Naquila ${ }^{1}$ and Shiella Mae B. Olimpos ${ }^{1}$

1. Biology and Environmental Studies Program, Sciences Cluster, University of the Philippines Cebu, Lahug, Cebu City, Philippines; 2. Southwestern University, Villa Aznar, Urgello St., Cebu City 6000, Philippines; 3. GPY Veterinare Animale Group of Veterinary Clinics, Cebu City 6000, Philippines.

Corresponding author: Adrian P. Ybañez, e-mail: dr.adrianpybanez@gmail.com, RHDY: rochelledybanez@gmail.com, RRV: rexvillavelez@gmail.com, HPFM: hp_dvm@yahoo.com,

DNMB: datbarrameda@gmail.com, SVN: sharmaine_naquila@yahoo.com,SMBO: olimpos.shiellamae@gmail.com Received: 04-09-2015, Revised: 28-11-2015, Accepted: 06-12-2015, Published online: 13-01-2016

doi: 10.14202/vetworld.2016.43-47 How to cite this article: Ybañez AP, Ybañez RHD, Villavelez RR, Malingin HPF, Barrameda DNM, Naquila SV, Olimpos SMB (2016) Retrospective analyses of dogs found serologically positive for Ehrlichia canis in Cebu, Philippines from 2003 to 2014, Veterinary World, 9(1): 43-47.

\begin{abstract}
Aim: The study aimed to document the clinical and hematological observations of dogs found serologically positive for Ehrlichia canis and to identify parameters or factors that are associated with the disease with focus on the anemic and thrombocytopenic state of the infected dogs.

Materials and Methods: From 7 participating veterinary establishments, a total of 913 cases from 2003 to 2014 were initially assessed using inclusion criteria, including E. canis diagnosis by the attending veterinarian and the presence of ticks or history of infestation, thrombocytopenia, and/or anemia. From these, 438 cases that were found serologically positive for E. canis using commercial test kits were selected. Profile, clinical observations and hematological test results were obtained from the selected cases. Computations for statistical associations between the anemic and thrombocytopenic state of the infected dogs and their profile, observed clinical signs and other hematological values were performed.

Results: Most of the dogs were purebred (60.0\%) and female (51.1\%) and were within the age range of 1-5 years (38.4\%). The mean packed cell volume (PCV), red blood cell (RBC) count, and platelet count were lower than the normal values while the absolute count of basophils were higher than normal values. Creatinine and blood urea nitrogen (BUN) appear to be elevated. The most common clinical signs observed were inappetence (41.3\%), lethargy/depression (35.6\%), vomiting (32.4\%), fever (18.5\%), paleness (8.2\%), and epistaxis (6.6\%). Analyses showed that there were no significant differences on the hematological values and clinical signs between thrombocytopenic and non-thrombocytopenic seropositive dogs. Moreover, very weak correlations between platelet count and RBC count, absolute lymphocyte count, and neutrophil count were found. On the other hand, only paleness $(\mathrm{p}=0.008)$ and epistaxis $(\mathrm{p}=0.004)$ were found to be significantly different between anemic and non-anemic patients. This coincided with the linear regression results where PCV $(\mathrm{p}=0.000, \mathrm{R}=0.787$, $\mathrm{R}^{2}=0.619$ ) was moderately correlated with the $\mathrm{RBC}$ count. In addition, eosinophil count was found weakly correlated.
\end{abstract}

Conclusion: E. canis infection in dogs may produce varied clinical signs that may be influenced by the thrombocytopenic and anemic states of affected animals. Complete blood counts remain important in the diagnosis of the disease, especially the platelet and RBC counts. Creatinine, BUN and alanine aminotransferase can be of value in the diagnosis of the infection. Several cases were lost to follow-up and appeared to be a challenge for handling veterinarians to monitor compliance of owners and progress of infected patients.

Keywords: Cebu, clinical signs, dog, Ehrlichia canis, hematology, Philippines.

\section{Introduction}

Canine ehrlichiosis or canine monocytic ehrlichiosis (CME) is a disease of major global significance that affects dogs. It is caused by Ehrlichia canis, a Gram-negative, coccoid to ellipsoidal, often pleomorphic, intracytoplasmic bacteria belonging to the family Anaplasmataceae [1]. It is transmitted by the ubiquitous brown dog tick, Rhipicephalus sanguineus

Copyright: Ybañez et al. Open Access. This article is distributed under the terms of the Creative Commons Attribution 4.0 International License (http://creativecommons.org/licenses/by/4.0/), which permits unrestricted use, distribution, and reproduction in any medium, provided you give appropriate credit to the original author(s) and the source, provide a link to the Creative Commons license, and indicate if changes were made. The Creative Commons Public Domain Dedication waiver (http://creativecommons.org/ publicdomain/zero/1.0/) applies to the data made available in this article, unless otherwise stated. complex [2,3]. Recently, E. canis has been detected in humans [4]. It infects the monocytes, granulocytes, and platelets [5].

E. canis may be detected together with Anaplasma platys, a bacteria transmitted by the same tick vector. Co-infection with this pathogen can lead to severe clinical signs [2,6]. CME can also produce non-specific clinical signs [5]. As CME can be a multi-systemic disease [6], it may manifest several clinical signs that can lead to disease misdiagnosis.

Molecular and serological evidence have validated the presence of E. canis in the Philippines [5,7-10]. As it can be life threatening, its timely recognition to institute immediate and appropriate therapy is vital for the survival of the affected animal [5]. Except for a case report by Ybañez [5], there are no other published 
researches documenting the clinical signs of CME cases in the Philippines. Collecting and gathering information detailing the most common clinical signs manifested in the area can be beneficial. Hence, this study endeavored to determine the profile of dogs and clinical signs that may be correlated with the thrombocytopenic and anemic states of infected dogs and assess the applicability of the neutrophil to lymphocyte ratio in predicting the outcome of CME disease.

\section{Materials and Methods}

\section{Ethical approval}

The study was performed in accordance with the Institutional Animal Care and Use Committee guidelines of Southwesern University, Cebu and the University of the Philippines Cebu, and with the approval of the attending veterinarians, chief veterinarians and/or proprietor of the veterinary establishments. The study relied on records and no animal was used in the conduct of the study.

\section{Veterinary establishments}

Several animal clinics and hospitals in Cebu, Philippines were invited to participate, but only 7 positively responded: (1) GPY Veterinare Animale-Main Branch, Cebu City, (2) AZYP Pet Doctor's Veterinary Center, Talisay City, (3) Pet Science Veterinary Center, Cebu City, (4) Animal Kingdom Veterinary Hospital, Cebu City, (5) George Animal Clinic, LapuLapu City, and (6) Mactan Animal Clinic, Lapu-Lapu City, Cebu, Philippines.

\section{Selection of CME cases}

A total of 913 cases from 2003 to 2014 were reviewed using inclusion criteria, including $E$. canis diagnosis by the attending veterinarian and the presence of ticks or history of infestation, thrombocytopenia, and/or anemia. From these, 475 and 438 cases were, respectively, considered as "suspected" and "validated" CME cases depending on whether or not the animal patients were tested for E. canis using a commercial test kit (Immunocomb ${ }^{\circledR}$, Biogal, Israel), with a reported sensitivity and specificity of $86 \%$ and $98 \%$, respectively [6]. Using a fixed survey form, the profile, clinical history, and laboratory test results of the validated CME cases were obtained. Moreover, presenting clinical signs, which were dependent on the attending veterinarian's observations, were also obtained from the clinical records.

\section{Data processing and analysis}

Data from the fixed survey form were manually tabulated in a tally sheet and then encoded to Microsoft Excel using appropriate coding to facilitate statistical analyses. Common clinical signs were identified while laboratory test results were summarized. Cases were grouped based on their anemic and thrombocytopenic states and were tested for associations against profile, laboratory test results and presenting clinical signs using Chi-square, logistic regression, analysis of variance and general linear model multivariate analyses.

\section{Results and Discussion}

Most of the dogs were of pure breed $(60.0 \%)$, female $(51.1 \%)$, and within the age range of $1-5$ years (38.4\%) (Table-1). In a study by Akhtardanesh et al. [11], no breed and sex predilection were found in seropositive dogs. Similarly, Harrus et al. [12] observed no age predilection in CME cases. In contrast to other studies, certain breeds were identified to be predisposed to certain clinical signs [13], like the case of German shepherds showing hemorrhagic signs (including epistaxis), and the Beagles and mongrels showing typical signs of the disease [14]. Further studies are needed to determine breed predispositions in the Philippine setting. On tick infestation, only $19.9 \%$ of the patients were noted to have the parasites, which is lower than previously reported $(52.7 \%)$ [15]. This indicates that the dog patients may have been exposed to ticks and the pathogen earlier. Thus, in CME diagnosis, the absence of ticks in the observed patient cannot rule out the possibility of infection.

Only $33 \%$ were noted to recover from the disease after treatment. In subclinical infections, dogs are able to spontaneously recover from the disease without treatment [16]. As more than the majority of the patients were lost to follow-up (63.0\%), it remains a big challenge for veterinarians to ensure that owners follow the suggested treatment protocol and allow pets to recover from the disease. If treatment is discontinued, infected dogs may enter into the chronic

Table-1: Profile of E. canis-seropositive dogs in Metro Cebu, Philippines $(n=438)$.

\begin{tabular}{lc}
\hline Parameter & $\mathbf{N}(\%)$ \\
\hline Breed & \\
Pure & $263(60.0)$ \\
Mixed & $143(32.6)$ \\
None-specified & $32(7.3)$ \\
Sex & \\
Female & $224(51.1)$ \\
Male & $183(41.8)$ \\
Not specified & $31(7.1)$ \\
Age & \\
>1 & $70(16.0)$ \\
$1-5$ years & $168(38.4)$ \\
Above 5 years & $59(13.5)$ \\
Not specified & $141(32.2)$ \\
Mean: 3.6 years, SD=10.9 & \\
Tick infestation & \\
Noted & $87(19.9)$ \\
Not noted & $351(80.1)$ \\
Recorded outcome & \\
Recovered & $133(30.4)$ \\
Dead & $29(6.6)$ \\
Lost to follow-up & $276(63.0)$ \\
Thrombocytopenic & \\
Yes & $316(72.1)$ \\
No & $45(10.3)$ \\
Lost data & $77(17.6)$ \\
Anemic & \\
Yes & $234(53.4)$ \\
No & $115(26.3)$ \\
Lost data & $89(20.3)$ \\
\hline E. canis=Ehrlichia canis, SD=Standard deviation \\
\hline
\end{tabular}


phase of CME. In chronic cases leading to death, treatment appears to have no effect to the outcome of the disease [16].

A high proportion of the dogs were thrombocytopenic and anemic (at least $72.14 \%$ and $53.4 \%$, respectively). Thrombocytopenia and anemia are considered the hallmarks of CME infection. Pancytopenia and leucopenia (only $5.7 \%$ and $7.3 \%$, respectively, in this study) reported by other studies were not commonly recorded observations [15,17-22].

The mean packed cell volume (PCV) and red blood cell (RBC) count were lower than the reference values. Waner et al. [23] also found low PCV and $\mathrm{RBC}$ in experimentally E. canis-infected dogs, but with no consistency. Similarly, platelet counts were lower than the reference values. Platelet count has been shown to be a good screening test for E. canis infection, with increasing reliability in relation to the degree of thrombocytopenia [24]. It is also used to assess recovery from the disease [25]. Platelet counts may be lower than normal because of the presence of anti-platelet serum during CME infection [26]. Meanwhile, differential and absolute counts of the white blood cells were within normal range, except for the absolute count of basophils. Basophil counts were found significantly higher in dogs infected with the closely related Anaplasma platys [27]. Basophils appear to participate in parasitic infections [28], but further studies are needed to determine its role in CME infection.

The average neutrophil to lymphocyte (N/L) ratio was 5.0 (standard deviation $[\mathrm{SD}]=9.2$ ). It was found to be a significant predictor on the outcome of the disease $(\mathrm{p}=0.011)$. Those which reportedly recovered or died from the disease had an average $\mathrm{N} / \mathrm{L}$ value of $3.7(\mathrm{SD}=4.1)$ and $12.0(\mathrm{SD}=20.1)$, respectively. To the best of the author's knowledge, this study is the first to describe $\mathrm{N} / \mathrm{L}$ as a predictor of CME outcome in dogs. The N/L has been used as a good prognostic marker that may also express disease severity [29].

Creatinine and blood urea nitrogen (BUN) appears to be elevated (Table-2). These are similar observations by that of Mylonakis et al. [22]. Although the mean alanine aminotransferase (ALT) value in this study was in normal range, its variability is very high between patients. Elevated ALT is a known observation in CME cases [19,22], which may be caused by liver-associated problems caused by the infection [30].

The most common clinical signs observed were inappetence $(41.3 \%)$, lethargy/depression $(35.6 \%)$, vomiting (32.4\%), fever (18.5\%), paleness $(8.2 \%)$, and epistaxis $(6.6 \%)$ (Table-3). In other studies, lethargy, epistaxis, apathy, anorexia, pale mucous membrane, lymphadenopathy, splenomegaly, and uveitis [30,31] were also observed. However, fever was not frequently observed by Inokuma et al. [20]. In a study by Stockham et al. [16], fever was shown to occur at 18-24 days after E. canis inoculation. In the same
Table-2: Hematological and biochemical values of E. canis-seropositive dogs in Metro Cebu, Philippines.

\begin{tabular}{lccc}
\hline Parameter & Mean & SD & $\begin{array}{c}\text { Reference } \\
\text { values }\end{array}$ \\
\hline Packed cell volume $(\%)$ & 33.6 & 16.9 & $35-57$ \\
Hemoglobin $(\mathrm{g} / \mathrm{dL})$ & 22.1 & 89.1 & $12-19$ \\
RBC $\left(\times 10^{6} / \mu \mathrm{L}\right)^{\mathrm{a}}$ & 4.7 & 1.8 & $5.0-7.9$ \\
Platelet $\left(\times 10^{3} / \mu \mathrm{L}\right)$ & 110.9 & 93.5 & $211-621$ \\
White blood cell $\left(\times 10^{3} / \mu \mathrm{L}\right)$ & 13.1 & 9.7 & $5.0-14.1$ \\
Differential count $(\%)$ & & & \\
$\quad$ Basophil & 5.6 & 10.5 & $0-1$ \\
Eosinophil & 7.2 & 13.8 & $0-9$ \\
Neutrophil & 65.0 & 22.0 & $58-85$ \\
Monocyte & 5.3 & 6.1 & $2-10$ \\
Lymphocyte & 24.1 & 18.1 & $8-21$ \\
Absolute count $\left(\times 10^{3} / \mu \mathrm{L}\right)$ & & & \\
$\quad$ Basophil & 0.4 & 0.5 & $0-0.1$ \\
Eosinophil & 0.9 & 1.6 & $0-1.3$ \\
Neutrophila & 0.7 & 1.1 & $0.1-1.4$ \\
Monocyte & 2.9 & 3.0 & $0.4-2.9$ \\
$\quad$ Lymphocyte & 9.0 & 8.4 & $2.9-12$ \\
Alanine aminotransferase $(\mathrm{u} / \mathrm{L})$ & 70.4 & 102.8 & $10-109$ \\
Creatinine $(\mathrm{mg} / \mathrm{dL})$ & 3.6 & 8.9 & $0.5-1.7$ \\
Blood urea nitrogen $(\mathrm{mg} / \mathrm{dL})$ & 29.3 & 48.7 & $8.0-28.0$ \\
\hline
\end{tabular}

aWeak correlation with platelet count, $p<0.05$, bWeak correlation with RBC count, $\mathrm{p}<0.05$. RBC $=$ Red blood cell, $\mathrm{SD}=$ Standard deviation, E. canis $=$ Ehrlichia canis

Table-3: Common clinical signs of E. canis seropositive dogs in Metro Cebu, Philippines $(n=438)$.

\begin{tabular}{lcc}
\hline Clinical sign & $\mathbf{n}$ & \% \\
\hline Inappetence & & 41.3 \\
Lethargy/depression & & 35.6 \\
Vomiting & 32.4 \\
Fever & & 18.5 \\
Paleness* & 8.2 \\
Epistaxis* & 6.6 \\
Diarrhea & 6.2 \\
Coughing & 5.9 \\
Anorexia & 3.2 \\
Opthalmological lesions & & 3.0 \\
Icterus & & 1.4 \\
Neurological signs & & 0.9 \\
Dyspnea & & 0.7 \\
Edema of the limbs & 3 & 0.7 \\
Ocular discharges & 3 & 0.7 \\
Nasal discharges & 2 & 0.5 \\
Scrotal edema & 2 & 0.5 \\
\hline
\end{tabular}

$* \mathrm{p}<0.05$; Moderate correlation with RBC count of $E$. canis seropositive dogs. $E$. canis $=$ Ehrlichia canis, $\mathrm{RBC}=\mathrm{Red}$ blood cell

manner, epistaxis was not consistently seen in infected patients. David et al. [32] suggested that it is the most dramatic sign of the disease in experimentally infected German shepherd dogs. Based on records, it can be deduced that not all the observed clinical signs with the highest frequency are congruent with the other reports. Thus, clinical signs of CME appear to be varied and non-specific. This may be attributed to the infection of E. canis to circulating monocytes, which affects different body systems and produce varied clinical signs or combinations [6]. CME can be multi-systemic affecting several organs [32]. It may also be due to the different disease stages of the presented animals [6]. 
Further analyses showed that there were no significant differences on the other hematological parameters between thrombocytopenic and non-thrombocytopenic dogs. Moreover, very weak correlations were found between platelet count and $\mathrm{RBC}$ count ( $\left.\mathrm{p}=0.047, \mathrm{R}=0.108, \mathrm{R}^{2}=0.012\right)$, absolute lymphocyte count $\left(\mathrm{p}=0.004, \mathrm{R}=0.155, \mathrm{R}^{2}=0.024\right)$ and neutrophil count $\left(\mathrm{p}<0.000, \mathrm{R}=0.210, \mathrm{R}^{2}=0.044\right)$. However, none of the clinical signs were found significantly related with the thrombocytopenic state of dogs. While PCV ( $\left.\mathrm{p}=0.000, \mathrm{R}=0.787, \mathrm{R}^{2}=0.619\right)$ was found correlated with the RBC count, only paleness $(p=0.008)$ and epistaxis $(p=0.004)$ were found to be significantly different between anemic and non-anemic patients. In addition, eosinophil count ( $\mathrm{p}=0.004, \mathrm{R}=0.360, \mathrm{R}^{2}=0.130$ ) was found to be weakly correlated with the RBC count. Ehrlichial morulae were already reported in the eosinophil of infected dogs [33]. Eosinophils are known to participate in the inflammation process [34] and parasitism [35].

There is a possibility that the clinical, hematological and biochemical findings of the patients were not only influenced by E. canis, but also by other pathogens transmitted by the same tick vector, including A. platys and Babesia gibsoni. Ticks have known the capability of hosting multiple pathogenic organisms [36], which can result in a co-infected dog [37]. Co-infection with other pathogens is not uncommon [22], which can produce severe signs [38] that can be fatal to the diseased patient [39]. It is difficult to associate a specific clinical sign or hematological abnormality to a particular canine vector-borne disease due to possibilities of co-infection [40]. Another consideration is the possibility of serological cross-reaction of E. canis with the zoonotic Anaplasma phagocytophilum [21]. With such assumption, some of the positive dogs may be infected with $A$. phagocytophilum instead of E. canis.

In all cases, peripheral blood smear examination (PBSE) was not recorded to be performed. Although with low reliability [41], PBSE as a method for detecting Ehrlichia infection is a relatively cheap alternative to the more expensive commercial test kits. Veterinarians should perform PBSE if condition warrants.

\section{Conclusion}

E. canis infection in dogs may produce varied clinical signs that may be influenced by the thrombocytopenic and anemic states of affected animals. Complete blood counts remain important in the diagnosis of the disease, especially the platelet and $\mathrm{RBC}$ counts. Creatinine, BUN, and ALT can be of value in the diagnosis of the infection. Several cases were lost to follow-up and appeared to be a challenge for handling veterinarians to monitor compliance of owners and progress of infected patients.

\section{Authors' Contributions}

APY and RHDY conceptualized the study, and analyzed and wrote the manuscript. RRV contributed in the data analysis. HPFM, DNMB, SVN, and SMBO collected the information from the different clinics. All authors read and approved the final manuscript.

\section{Acknowledgments}

The authors would like to thank the veterinarians and staff of the GPY Veterinare Animale- Group of Veterinary Clinics, Dr. Gaudiosa M. Berdon and staff from the Animal Kingdom Veterinary Hospital, Dr. Jocelyn A. Tingson, Dr. Ryan S. Yandug and Dr. MaxFrancis G. Talle of Southwestern University for their support, assistance and valuable inputs to the study, and the Merial Animal Health-Philippines for the research grant.

\section{Competing Interests}

The authors declare that they have no competing interests.

\section{References}

1. Dumler, S.J., Barbet, A.F., Bekker, C.P., Dasch, G.A., Palmer, G.H., Ray, S.C., Rikihisa, Y. and Rurangirwa, F.R. (2001) Reorganization of genera in the families' Rickettsiaceae and anaplasmataceae in the order Rickettsiales: Unification of some species of Ehrlichia with Anaplasma, Cowdria with Ehrlichia and Ehrlichia with Neorickettsia, descriptions of six new species combinations and designation of Ehrlichia equi and 'HGE agent' as subjective synonyms of Ehrlichia phagocytophila. Int. J. Syst. Evol. Microbiol., 51: 2145-2165.

2. Ybañez, A.P., Perez, Z.O., Gabotero, S.R., Yandug, R.T., Kotaro, M. and Inokuma, H. (2012) First molecular detection of Ehrlichia canis and Anaplasma platys in ticks from dogs in Cebu, Philippines. Ticks Tick Borne Dis., 3: $287-292$

3. Groves, M.G., Dennis, G.L., Amyx, H.L. and Huxsoll, D.L. (1975) Transmission of Ehrlichia canis to dogs by ticks (Rhipicephalus sanguineus). Am. J. Vet. Res., 36: 937-940.

4. Perez, M., Bodor, M., Zhang, C., Xiong, Q. and Rikihisa, Y. (2006) Human infection with Ehrlichia canis accompanied by clinical signs in Venezuela. Ann. New York Acad. Sci., 1078: 110-117.

5. Ybañez, A.P. (2014) First molecular evidence of Ehrlichia canis infection in dogs with probable disease relapse in the Philippines. J. Adv. Vet. Res., 4: 184-188.

6. Waner, T. and Harrus, S. (2000) "Canine monocytic ehrlichiosis (CME)." Recent advances in canine infectious diseases. International Veterinary Information Service, Ithaca, NY.

7. Baticados, A.M. and Baticados, W.N. (2011) Serological evidence of Ehrlichia canis exposure in military dogs and other canines in Metropolitan Manila, Philippines. Israel J. Vet. Med., 66: 151-156.

8. Baticados, A.M., Baticados, W.N., Villarba, L.A., Carlos, E.T., Carlos, S. and Fajardo, P.V. (2011) PCR assay and microscopy for examination of mixed Ehrlichia canis and Babesia spp. infection in bomb sniffing dogs and other canines in the National Capital Region, Philippines. Eurasian J. Vet. Sci., 27: 111-115.

9. Corales, J.M.I., Viloria, V.V., Venturina, V.M. and Mingala, C.N. (2014) The prevalence of Ehrlichia canis, Anaplasma platys and Babesia spp. in dogs in Nueva Ecija, Philippines based on multiplex polymerase chain reaction (mPCR) assay. Ann. Parasitol., 60: 267-272. 
10. Ybañez, A.P., Ybañez, R.H.D., Yokoyama, N. and Inokuma, H. (2015) RNA polymerase sub-unit $\beta$ (rpoB) characterization of Ehrlichia canis detected from dogs and Rhipicephalus sanguineus ticks in Cebu, Philippines. Vet. Arch., 85: 601-608.

11. Akhtardanesh, B., Blourizadeh, H. and Ghanbarpour, R. (2010) Serological evidence of canine monocytic ehrlichiosis in Iran. Comp. Clin. Pathol., 19: 469-474.

12. Harrus, S., Kass, P.H., Klement, E. and Waner, T. (1997) Canine monocytic ehrlichiosis: A retrospective study of 100 cases, and an epidemiological investigation of prognostic indicators for the disease. Vet. Rec., 141: 360-363.

13. McDade, J.E. (1990) Ehrlichiosis-a disease of animals and humans. J. Infect. Dis., 161: 609-617.

14. Amyx, H.L. and Huxsoll, D.L. (1973) Red and gray foxes- potential reservoir host for Ehrlichia canis. J. Wildlife Dis. 9: 47-50.

15. Dagnone, A.S., De Morais, H.S.A., Vidotto, M.C., Jojima, F.S. and Vidotto, O. (2003) Ehrlichiosis in anemic, thrombocytopenic, or tick-infested dogs from a hospital population in South Brazil. Vet. Parasitol., 117(4): 285-290.

16. Stockham, S.L., Tyler, J.W., Schmidt, D.A. and Curtis, K.S. (1990) Experimental transmission of granulocytic ehrlichial organisms in dogs. Vet. Clin. Pathol., 19: 99-104.

17. Abete, J., Ackerson, K., Gessner, A., Jaegersen, K., Kaltenboeck, B., Kelly, P., Loftis, A., Lucas, H., Stevens, A., Wang, C. and $\mathrm{Xu}, \mathrm{C}$. (2013) Ehrlichiosis, babesiosis, anaplasmosis and hepatozoonosis in dogs from St. Kitts, West Indies. PLoS One, 8(1): e53450.

18. Amimoto, A., Baba, K., Hiraoka, H., Itamoto, K., Kitagawa, K. and Mizuno, T. (2012) Ehrlichia canis infection in two dogs that emigrated from endemic areas. J. Vet. Med. Sci., 74: 775-778.

19. Anuchai, N., Somporn, T. and Siramm, S. (2006) A retrospective study of the clinical hematology and biochemistry of canine ehrlichiosis in an animal hospital population in Bangkok, Thailand. Comp. Clin. Pathol., 14: 217-220.

20. Inokuma, H., Okuda, M., Tsu, M. and Watanabe, M. (2004) Seroepidemiological study of canine Ehrlichial infections in Yamaguchi prefecture and surrounding areas of Japan. Vet. Parasitol., 124: 101-107.

21. Waner, T., Strenger, C., Keysary, A. and Harrus, S. (1998) Kinetics of serologic cross-reactions between Ehrlichia canis and the Ehrlichia phagocytophila genogroups in experimental E. canis infection in dogs. Vet. Immunol. Immunopathol., 66: 237-243.

22. Mylonakis, M.E., Koutinas, A.F., Breitschwerdt, E.B., Hegarty, B.C., Billinis, C.D., Leontides, L.S. and Kontos, V.S. (2004) Chronic canine ehrlichiosis (Ehrlichia canis): A retrospective study of 19 natural cases. J. Am. Anim. Hosp. Assoc., 40: 174-184.

23. Waner, T., Harrus, S., Bark, H., Bogin, E., Avidar, Y. and Keysary, A. (1997) Characterization of the subclinical phase of canine ehrlichiosis in experimentally infected beagle dogs. Vet. Parasitol., 69: 307-317.

24. Bulla, C., Takahira, R.K., Araújo, J.P. Jr., Aparecida, T. L., Lopes, R.S., Wiedmeyer, C.E. (2004) The relationship between the degree of thrombocytopenia and infection with Ehrlichia canis in an endemic area. Vet. Res., 35: 141-146.

25. Harrus, S., Waner, T., Aizenberg, I. and Bark, H. (1998) Therapeutic effect of doxycycline in experimental subclinical canine monocytic ehrlichiosis: Evaluation of a 6-week course. J. Clin. Microbiol., 36: 2140-2142.

26. Harrus, S., Waner, T., Keysary, A., Aroch, I., Voet, H. and Bark, H. (1998) Investigation of splenic functions in canine monocytic ehrlichiosis. Vet. Immunol. Immunopath., 62: 15-27.

27. Lasta, C.S., dos Santos, A.P., Messick, J.B., Oliveira, S.T., Biondo, A.W., da Costa, Vieira, R.F., Dalmolin, M.L. and Gonzalez, F.H.D. (2013) Molecular detection of Ehrlichia canis and Anaplasma platys in dogs in Southern Brazil. Rev. Bras. Parasitol. Vet., 22: 360-366.

28. Voehringer, D. (2009) The role of basophils in Helminth infection. Trends Parasitol., 25: 551-556.

29. Kučer, N., Matijatko, V., Kiš, I., Grden, D., Brkljačić, M., Foršek, J., Žvorc, Z. and Rafaj, R.B. (2008) White blood cell count and neutrophil to lymphocyte ratio in uncomplicated and complicated canine babesiosis caused by Babesia canis canis. Vet. Arch., 78: 321-330.

30. Nakaghi, A.C.H., Machado, R.Z., Costa, M.T., André, M.R. and Baldani, C.D. (2008) Canine ehrlichiosis: Clinical, hematological, serological and molecular aspects. Ciên. R., 38: 766-770.

31. Kordick, S.K., Breitschwerdt, E.B., Hegarty, B.C., Southwick, K.L., Colitz, C.M., Hancock, S.I. and MacCormack, J.N. (1999) Coinfection with multiple tick-borne pathogens in a Walker Hound kennel in North Carolina. J. Clin. Microbiol., 37: 2631-2638.

32. Aroch, I., Bark, H., Harrus, S. and Lavy, E. (1997) Clinical manifestations of infectious canine cyclic thrombocytopenia. Vet. Rec., 141: 247-250.

33. David, L., Huxsollpaul, K., Hildebrandtrobert, M., Nimsherbert, L., Amyxjames, A. and Ferguson, J.A. (1970) Epizootiology of tropical canine pancytopenia. J. Wildlife Dis., 6: 220-225.

34. Stockham, S.L., Schmidt, D.A., Curtis, K.S., Schauf, B.G., Tyler, J.W. and Simpson, S.T. (1992) Evaluation of granulocytic ehrlichiosis in dogs of Missouri, including serologic status to Ehrlichia canis, Ehrlichia equi and Borrelia burgdorferi. Am. J. Vet. Res., 53: 63-68.

35. Sampson, A.P. (2000) The role of eosinophils and neutrophils in inflammation. Clin. Exp. Allergy, 30: 22-27.

36. Mawhorter, S.D. (1994) Eosinophilia caused by parasites. Pediatr. Ann., 23: 405, 409-413.

37. Breitschwerdt, E.B., Hegarty, B.C. and Hancock, S.I. (1998) Sequential evaluation of dogs naturally infected with Ehrlichia canis, Ehrlichia chaffeensis, Ehrlichia equi, Ehrlichia ewingii, or Bartonella vinsonii. J. Clin. Microbiol., 36: 2645-2651.

38. Gaunt, S.D., Beall, M.J., Stillman, B.A., Lorentzen, L., Diniz, P.P.V.P., Chandrashekar, R. and Breitschwerdt, E.B. (2010) Experimental infection and co-infection of dogs with Anaplasma platys and Ehrlichia canis: Hematologic, serologic and molecular findings. Parasit. Vectors, 3: 33.

39. Gal, A., Harrus, S., Arcoh, I., Lavy, E., Aizenberg, I., Mekuzas-Yisaschar, Y. and Baneth, G. (2007) Coinfection with multiple tick-borne and intestinal parasites in a 6-week-old dog. Can. Vet. J., 48: 619-622.

40. de Caprariisa, D., Dantas-Torresa, F., Capellib, G., Menckec, N., Stanneckc, D., Breitschwerdt, E.B. and Otrantoa, D. (2011) Evolution of clinical, haematological and biochemical findings in young dogs naturally infected by vector-borne pathogens. Vet. Microbiol., 149: 206-212.

41. Ramos, C.A., Ramos, R.A., Araújo, F.R., Guedes, D.S. Jr, Souza, I.I., Ono, T.M., Vieira, A.S., Pimentel, D.S., Rosas, E.O., Faustino, M.A. and Alves, L.C. (2009) Comparison of nested-PCR with blood smear examination in detection of Ehrlichia canis and Anaplasma platys in dogs. Braz. J. Vet. Parasitol. 1: 58-62. 